\title{
Idoso, família e domicílio: uma revisão narrativa sobre a decisão de morar sozinho
}

\author{
Mirela Castro Santos Camargos* \\ Roberto Nascimento Rodrigues** \\ Carla Jorge Machado***
}

\begin{abstract}
Neste artigo procura-se estabelecer bases de argumentação para melhor entender as razões que levam um idoso a morar sozinho e como se processam as transferências (fluxo de recursos, ações e informações que se trocam e circulam) quando vive sozinho. Para tanto, são revisados e discutidos fatores determinantes dos arranjos domiciliares dos idosos, incluindo aspectos demográficos, socioeconômicos e de saúde, com ênfase nos domicílios unipessoais. Destacamse pontos que permeiam as transferências entre idosos e seus familiares, tais como características das transferências intergeracionais, diferenças entre os diversos apoios recebidos, sexo do idoso. O estudo consistiu de uma revisão narrativa, cujos resultados apontaram que melhores condições socioeconômicas e de saúde, idade mais avançada e ausência de filhos parecem contribuir para que o idoso more sozinho. Contudo, houve divergências nos resultados dos estudos analisados quanto aos fatores associados à formação de domicílios unipessoais de idosos. Embora as transferências possam se dar independentemente do arranjo domiciliar do idoso, as que ocorrem entre os membros de um mesmo domicílio parecem ser mais frequentes e, talvez por isso, mais discutidas. Os idosos que moram sozinhos, apesar de participarem das transferências, estão mais propensos a receber cuidado formal, comparativamente àqueles que residem com outras pessoas.
\end{abstract}

Palavras-chave: Idosos. Domicílios unipessoais. Família.

\section{Introdução}

Na maioria dos países, incluindo o Brasil, verifica-se tanto em números absolutos quanto relativos um aumento de domicílios unipessoais para a população de 60 anos e mais (UNITED NATIONS, 2005; IBGE, 2007). Entender as razões que levam os idosos a constituírem ou permanecerem em domicílios unipessoais, causando mudanças significativas na conformação dos arranjos domiciliares e familiares, assim como na sua interação com os demais membros da família e do conjunto da sociedade, tem-se tornado tema de interesse na demografia.

Neste trabalho de revisão narrativa, são abordadas duas questões importantes para entender o que leva os idosos a morarem sozinhos e as estratégias de sobrevivência adotadas diante de dificuldades físicas e econômicas: os arranjos domiciliares de idosos; e as transferências entre os idosos e

\footnotetext{
* Doutora em Demografia pelo Cedeplar/UFMG, gestora em ensino e pesquisa da Fundação João Pinheiro.

${ }^{* *}$ PhD pela Australian National University, professor titular da Universidade Federal de Minas Gerais.

${ }^{* * *}$ PhD pela Johns Hopkins University, professora adjunta do Departamento de Demografia - Cedeplar/UFMG.
} 
seus familiares. Assim, na primeira parte do texto, procura-se analisar o que influencia a formação dos arranjos domiciliares entre os idosos, para identificar os aspectos relacionados a morar sozinho. Considerando-se que, na velhice, o indivíduo fica mais suscetível a precisar de suporte (funcional, financeiro ou emocional) e que a família ainda é a grande provedora de apoio ao idoso, na segunda parte desta revisão, explicita-se como ocorre o intercâmbio entre o idoso e seus familiares. São focalizados também os laços de parentesco e as transferências familiares.

\section{Arranjos domiciliares de idosos: 0 crescimento dos domicílios unipessoais}

\section{Hipóteses para a formação de domicílios unipessoais}

Ao se focalizar a população de 15 anos e mais, algumas hipóteses para explicar a tendência à formação de domicílios unipessoais podem ser mencionadas, entre as quais se destacam: aumento da renda real do indivíduo, permitindo arcar com os custos envolvidos na decisão de morar sozinho; inexistência de uma rede de parentesco, dificultando a divisão do domicílio com parentes; mudança nos gostos e preferência por privacidade; redução da privacidade em domicílios mais populosos; diminuição dos serviços domiciliares, com queda na qualidade e na quantidade das atividades domésticas; e redução da dependência do indivíduo em relação aos outros para auferir economias de escala no consumo de determinados bens e para obter companhia e entretenimento, devido à modernização tecnológica e ao avanço da urbanização (CAMPOS, 1998). Além dessas hipóteses, Kramarow (1995) menciona outras de aspectos culturais, como adoção do individualismo em detrimento das obrigações familiares.

Especificamente entre os idosos, a situação familiar, ou domiciliar, reflete o efeito acumulado de eventos demográficos, socioeconômicos e de saúde ocorridos em etapas anteriores do ciclo vital. O tamanho da prole, a mortalidade diferencial, o celibato, a viuvez, as separações, os recasamentos e as migrações conformam, ao longo do tempo, tipos distintos de arranjos familiares ou domésticos, que podem colocar o idoso, do ponto de vista emocional e material, em situação de segurança ou de vulnerabilidade (BERQUÓ, 1996). Morar sozinho ou com parentes pode ser resultado de desenlaces ou celibato, da não existência de prole, do falecimento dos filhos ou ainda da decisão de não viver com os filhos ou com qualquer outra pessoa, caso tenha recursos para tanto (BERQUÓ, 1996).

A Figura 1 apresenta exemplos de eventos que podem resultar na formação de domicílios unipessoais, considerando-se a fecundidade, a mortalidade, o casamento e os tipos de relações sociais de convivência.

Independentemente da origem ou da situação que leva à formação de domicílios unipessoais, destaca-se que a forma como os arranjos domiciliares vão se conformando varia entre as diversas regiões, países e características individuais. Estudo realizado pela Organização das Nações Unidas (ONU) analisou os arranjos domiciliares dos idosos, apresentando dados comparativos de 130 países (UNITED NATIONS, 2005). As principais conclusões desse estudo foram:

- aproximadamente uma em cada sete pessoas idosas (90 milhões) vive sozinha e cerca de dois terços delas são mulheres;

- existe uma tendência a favor de modalidades de vida independente (sozinho ou somente com o cônjuge), mais consolidada em países desenvolvidos;

- há menor proporção de mulheres idosas casadas (45\%), comparativamente aos homens (80\%);

- embora nos países desenvolvidos o arranjo mais comum seja morar separado dos filhos, naqueles em desenvolvimento a maioria dos idosos vive com seus filhos;

- em vários países desenvolvidos a institucionalização é uma opção para aqueles com dificuldade de se manterem independentes ou para aqueles que necessitam de cuidados médicos; 
FIGURA 1

Situações que levam à formação de domicílios unipessoais, considerando fecundidade, mortalidade, casamento e tipos de relações sociais de convivência

Situação anterior

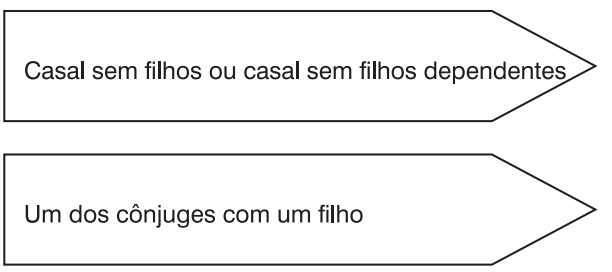

Um indivíduo vivendo com família ou amigos

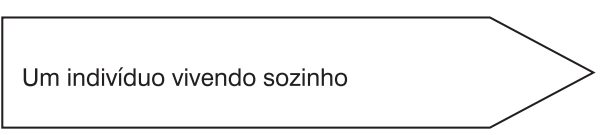

Casal com filhos

Fonte: Adaptado de Berquó e Cavenagui (1988, p.163).

- em países com altas taxas de infecção pelo HIV (human immunodeficiency virus ou vírus da imunodeficiência humana) tem aumentado o número de idosos que vivem com seus netos, mas não com seus filhos.

O estudo da ONU mostra que, nos países mais desenvolvidos, a proporção de idosos vivendo com os filhos diminui substancialmente com o avançar da idade. Em contrapartida, em muitos países em desenvolvimento, a porcentagem de pessoas idosas que moram com os filhos continua elevada, mesmo com o aumento da longevidade, sugerindo que os pais tendem a viver com pelo menos um dos filhos durante todo o ciclo de vida. Observa-se que, quanto maior o nível de desenvolvimento econômico do país, menores são as taxas de co-residência entre os idosos. En-

\section{Evento que leva a morar sozinho}

Separação ou divórcio, ou morte de um dos cônjuges

Filho sai de casa ou morte do filho

Sai para morar sozinho ou amigos saem e o deixam sozinho

Permanece morando sozinho

Separação ou divórcio e um dos cônjuges sai com os filhos para formar outra unidade domiciliar

\footnotetext{
1 Para construir os arranjos domiciliares, foram utilizadas informações do Censo Demográfico 2000 sobre o total de moradores no domicílio. Foi classificado como "morando sozinho" o indivíduo pertencente a domicílio cujo total de moradores é igual a um.
} 
Brasil. A região Norte registrou as menores proporções de idosos vivendo sozinhos, com destaque para o Estado do Amazonas. Em 2000, as Regiões Sul, Sudeste e Centro-Oeste apresentaram praticamente a mesma porcentagem $(12,8 \%)$ de idosos morando sozinhos.

Ainda de acordo com o IBGE (2007), o número de idosos que moram sozinhos no Brasil vem crescendo sistematicamente, alcançando, em 2006, 13,2\% desse segmento. A população de 60 anos e mais, em 2006, foi responsável por $40,3 \%$ dos domicílios unipessoais brasileiros.

\section{Fatores associados à formação dos arranjos domiciliares de idosos}

\section{Aspectos regionais}

Bongaarts e Zimmer (2002), utilizando dados de 43 países que participaram da Pesquisa de Demografia e Saúde (DHS) entre 1990 e 1998 (nos continentes da África, Ásia e América Latina), selecionaram pessoas idosas, de 65 anos e mais, que viviam sozinhas. Os autores constataram que as mulheres idosas possuíam maiores chances de morarem sozinhas e menores chances de viverem com o cônjuge e de serem o chefe ou pessoa de referência do domicílio, quando comparadas aos homens idosos. A co-residência com filhos adultos era mais comum nos países asiáticos e menos frequente nos africanos. Na América Latina, os pais idosos tendiam a co-residir mais com as filhas, diferentemente da Ásia e da África, onde a co-residência era mais comum com os filhos do sexo masculino. Mesmo existindo algumas características comuns, os arranjos domiciliares variaram entre as três regiões e mesmo internamente entre os diversos países. Tais variações estão associadas a um conjunto de fatores, de naturezas demográfica, socioeconômica, culturais e de saúde.

\section{Aspectos demográficos}

\section{Sexo e estado conjugal}

Há evidências de que o sexo e o estado conjugal estão interligados na conformação do arranjo domiciliar do idoso. Segundo Glaser (1997), por apresentarem maior expectativa de vida ao longo de todo o ciclo vital, em geral, as mulheres idosas passam uma grande parte de suas vidas como viúvas, com maior chance de viverem sozinhas. Ao analisar os dados da PNAD de 1998, Romero (2002) destaca que, no Brasil, os arranjos familiares dos idosos (nesse caso consideradas as pessoas com 65 anos e mais) e a condição que ocupam no domicílio são distintos entre os sexos. Segundo a autora, a maioria dos homens idosos mora com seu cônjuge $(80,9 \%)$ e apenas $8,7 \%$ vivem sozinhos. Já as mulheres distribuem-se em diversos tipos de arranjos: $46 \%$ vivem com seu cônjuge; $23,5 \%$ moram com os filhos e sem o cônjuge; $13,7 \%$ residem apenas com um parente; e 16,7\% vivem sozinhas. A grande discrepância em relação ao status marital, com um elevado número de viúvas, em contraste com alto percentual de homens casados, faz com que as mulheres idosas tenham maiores chances de enfrentar o declínio da capacidade física e mental sem apoio do marido (no caso de viúvas e descasadas) e de filhos, no caso das solteiras (BERQUÓ, 1996).

Neri (2005) analisou, em termos conjugais, características associadas ao fato de uma pessoa estar sozinha (solteira, viúva ou descasada) ou acompanhada (casada ou unida consensualmente). Introduzindo a idade como uma nova variável na análise, no Brasil, em 1970 e em 2000, foram observados comportamentos conjugais distintos entre os sexos. Os resultados indicam que as mulheres atingem maiores taxas de solidão² em idades mais avançadas, ao passo que, para os homens, essas taxas são maiores

\footnotetext{
2 A taxa de solidão refere-se ao número de pessoas solteiras, viúvas e descasadas de determinado grupo de idade sobre o total de pessoas naquela faixa etária. Solidão, aqui, diz respeito tão somente a estar solteiro(a), viúvo(a) ou descasado(a), por vontade própria ou por abandono, sem qualquer conotação com o sentimento de estar só.
} 
na juventude. Em 2000, entre as pessoas com 60 anos e mais, a taxa de solidão para as mulheres chegou a 2,6 vezes a dos homens. Além da maior longevidade feminina, o autor sugere como explicações para os resultados observados a maior preferência de homens por mulheres mais jovens (e/ ou vice-versa) e a maior independência feminina conquistada nos últimos anos, decorrente do aumento da profissionalização das mulheres, redução da desigualdade de renda entre os sexos e maiores frequências de dissoluções conjugais.

Idade

Entre os idosos mais velhos, as chances de ficarem viúvos e, consequentemente, viverem sozinhos são maiores, contudo, eles apresentam maior prevalência de incapacidade funcional (CAMARGOS, 2004), o que aumenta a necessidade de ajuda de outras pessoas e as chances de opção pela co-residência. Ou seja, a idade é um indicador que deve ser analisado com cuidado. Adicionalmente, para Avery, Speare Jr. e Lawton (1989), a idade pode atuar na percepção e aceitação dos arranjos domiciliares nos quais estão inseridos. Ou seja, para uma pessoa de 85 anos pode ser mais fácil aceitar suas limitações e necessidades de ajuda e optar pela co-residência ou mesmo pela institucionalização, comparativamente a um idoso de 65 anos.

\section{Residência urbana ou rural}

A formação de arranjos domiciliares de idosos também pode ser influenciada pelo local de residência (urbana ou rural). Devido ao caráter seletivo do processo de urbanização, com uma maior saída da população em idade ativa, seria razoável pressupor que, nas áreas rurais, os idosos teriam diminuídas as chances de co-residir, o que poderia aumentar as probabilidades de morarem sozinhos. Entretanto, é importante considerar que, nessas áreas, os valores tradicionais da família ainda se mantêm bastante fortes, podendo dificultar a formação de domicílios independentes. Com efeito, em Minas Gerais, Camargos, Machado e Rodrigues (2006) observaram que as idosas moradoras de área rural apresentavam, significativamente, chance $20 \%$ menor de morarem sozinhas, em relação às residentes em áreas urbanas. No entanto, este efeito de urbanização sobre o arranjo familiar não foi verificado por Bongaarts e Zimmer (2002) em estudos com idosos africanos, asiáticos e latino-americanos.

\section{Escolaridade}

Bongaarts e Zimmer (2002) destacaram que a escolaridade se mostrou importante fator associado para a escolha por arranjos domiciliares mais nucleares. Quanto mais elevado o nível de escolaridade, maior a quantidade de idosos em domicílios com menor número de pessoas, ou com poucas crianças e filhos adultos, e maior a probabilidade de o idoso morar sozinho. Os autores argumentam que idosos com maiores níveis de escolaridade geralmente apresentam maior habilidade para cuidar de si mesmos, possuem maior poder de compra e têm coberturas social e de saúde mais adequadas. A importância da escolaridade na habilidade de idosos morarem sozinhos também foi observada por Avery, Speare Jr. e Lawton (1989), nos Estados Unidos, Cameron (2000), na Indonésia, Camargos, Machado e Rodrigues (2006), em Minas Gerais, Saad (2003) e Camargos, Machado e Rodrigues (2007), no município de São Paulo.

\section{Renda}

A residência em domicílio unipessoal está diretamente associada à renda. Para Kinsella e Velkoff (2001), as melhorias nas condições financeiras podem permitir que uma grande proporção de idosos torne-se apta a viver sozinha, exercendo sua escolha por independência e, ao mesmo tempo, mantendo contato com a família e redes de apoio. Ainda em relação à renda, um estudo realizado por McGarry e Schoeni (2000) mostra que o crescimento dos benefícios (tais como infraestrutura e aumento dos serviços públicos no atendimento ao idoso) é o principal fator associado à expansão do número de idosas vivendo sozinhas nos Estados Unidos, no século XX, explicando 47\% desse aumento entre 1940 e 1990. 
Analisando os domicílios com idosos no município de Belo Horizonte, em 1991, Ferreira (2001) observou que, ao variar a renda positivamente, aumentaram de forma significativa as probabilidades de ocorrência de domicílios unipessoais. Para o autor, quando ocorre um crescimento dos rendimentos domiciliares, existe uma tendência de valorização da privacidade, reduzindo-se as probabilidades de ocorrências dos domicílios com algum tipo de extensão, mesmo isolando o fato de o domicílio se localizar em uma favela.

Outros dois estudos recentes para o Brasil (CAMARGOS; MACHADO; RODRIGUES, 2006; CAMARGOS; MACHADO; RODRIGUES, 2007) observaram que as chances de o idoso morar sozinho crescem com o aumento da renda, mesmo controlando por variáveis demográficas, socioeconômicas e de saúde.

Não obstante estas evidências, Andrade e De Vos (2002) ponderam que a utilização isolada dessa variável para determinar a composição dos domicílios pode negligenciar o fato de que a composição do domicílio também sofre influências culturais e que há diferenças entre as sociedades. Assim, mesmo que a família ou o idoso disponha de renda suficiente para que viva sozinho, pode ser que, por valores culturais, esta escolha se torne pouco provável. Além disso, no caso de países menos desenvolvidos, os serviços de cuidado ao idoso ainda não são muito explorados pelo mercado, sendo pouco disponíveis. Cameron (2000), após analisar os fatores relacionados à escolha pelo arranjo domiciliar entre idosos da Indonésia, salienta que não é possível saber se os arranjos independentes são desejados pelos indonésios, pois altas rendas não estão associadas com baixos índices de co-residência.

\section{A incapacidade funcional e aspectos de} saúde

A necessidade de auxílio - físico, financeiro ou afetivo - faz com que muitos idosos deixem de viver de forma independente para morar com suas famílias. A incapacidade, funcional ou cognitiva, tende a tornar o idoso mais carente de cuidado e, consequentemente, mais suscetível a novos arranjos domiciliares de suporte. Ou seja, seria esperado, então, que idosos que vivem sós apresentassem melhores condições de saúde, menor número de doenças, bem como melhor desempenho funcional, aspectos importantes para que o idoso consiga se manter sozinho. Entretanto, um outro argumento seria válido e implicaria afirmar que idosos que vivem sozinhos teriam uma pior condição de saúde, por não terem alguém que os ajudasse nas atividades rotineiras, servisse de companhia e cuidasse deles em casos de necessidade. Assim, não é possível estabelecer um padrão claro. Para Romero (2002), não se sabe qual a combinação de suporte e estrutura domiciliar que mais favorece a saúde dos idosos.

$\mathrm{Na}$ perspectiva de entender essa vulnerabilidade dos idosos, lliffe et al. (1992) avaliaram se idosos londrinos que moravam sozinhos seriam um grupo de risco, com alto índice de morbidade e demandas por serviços sociais e de saúde. Não foram encontradas diferenças entre idosos que moravam sozinhos e acompanhados, em relação a problemas cognitivos, número de problemas físicos, déficit de mobilidade e uso de serviços de saúde. Ademais, aqueles que moravam sozinhos tendiam a relatar, com maior frequência, satisfação com a vida. Os autores também verificaram que as mulheres e os idosos de 80 anos e mais apresentavam maiores chances de viverem sós.

Ainda na perspectiva da relação entre condições de saúde e a formação de arranjos domiciliares de idosos, o estudo de Gliksman et al. (1995), analisando australianos de ambos os sexos, com 65 anos e mais, procurou estabelecer se havia influência do arranjo domiciliar, do suporte social e do estado conjugal em fatores de risco para doenças cardiovasculares. Os resultados indicaram que o suporte social, medido pelo contato com familiares, amigos e pessoas da comunidade, não esteve significativamente associado a fatores de risco para doenças cardiovasculares nessa população. Entretanto, características sociodemográficas tiveram significância estatística. Homens 
que viviam sozinhos apresentaram maiores medidas de pressão arterial. O estado conjugal também foi importante preditor de fatores de risco no caso dos homens, mas não para as mulheres.

\section{Transferências entre idosos e seus familiares}

As transferências podem ser consideradas um fluxo de recursos, ações e informações que se trocam e circulam (GUZMÁN; MONTES DE OCA, 2003). Um exemplo de transferência seriam os recursos financeiros dos pais para os filhos em idade escolar, que seriam contrabalançados no futuro por ajuda dos filhos aos pais na velhice. Segundo Guzmán e Montes de Oca (2003), existem quatro categorias de transferência ou apoio: material (dinheiro, alojamento, roupa, comida e pagamento de serviços); instrumental (cuidado, transporte e serviços domésticos); emocional (afeto, companhia, empatia, reconhecimento e escuta); e cognitivo (trocas de experiências, informações e conselhos). Em relação às fontes de apoio, os autores distinguem as formais, com objetivos específicos e profissionais ou voluntários que garantam suas metas, das fontes informais, constituídas por redes pessoais ou comunitárias não estruturadas como programa de apoio. Na Figura 2 estão esquematizadas as diferentes fontes de apoio que os indivíduos podem receber.

As transferências e ajuda mútua entre pais e filhos são o principal fator que tem assegurado, ao longo da história, a sobrevivência nas idades mais avançadas (SAAD, 1999). O intercâmbio de ajuda entre pais e filhos tende a se estender ao longo do ciclo de vida familiar, como se existisse um contrato intergeracional que estipulasse o papel de cada membro a cada fase do ciclo (SAAD, 1999).

No caso brasileiro, os cuidados aos idosos são prestados predominantemente por suas famílias e, na falta destas, por amigos e vizinhos (AQUINO; CABRAL, 2002).

FIGURA 2

Tipos de fontes de apoio existentes na sociedade

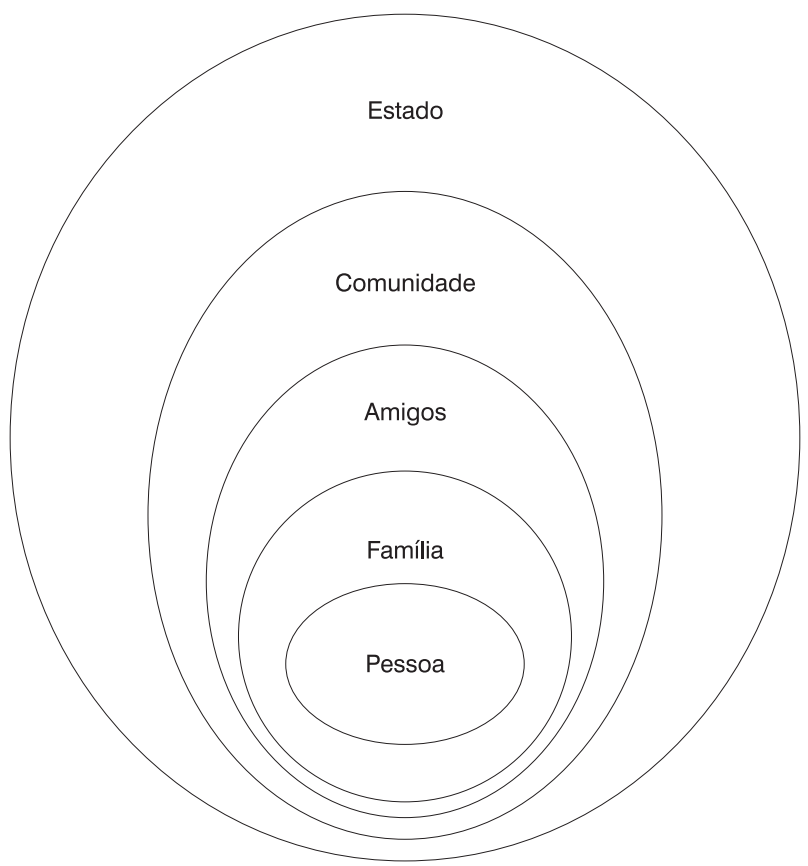

Fonte: Adaptado de Guzmán e Montes de Oca (2003, p.8). 
Ainda não existem programas formais por parte do Estado para prestar assistência aos idosos que não possuem auxílio da família ou recursos financeiros e necessitam de apoio. Para os que não podem contar com a ajuda informal, a institucionalização ainda é a principal alternativa.

Para Ramos (2002), o equilíbrio na relação entre o cuidador e o receptor de cuidado pode promover, de várias formas, melhores condições de saúde para o idoso. Porém, certos desequilíbrios podem desencadear efeitos negativos sobre a saúde desses indivíduos. Neste caso, devido à percepção de dependência, falta de autonomia e inabilidade em retribuir a ajuda recebida, o idoso pode ter sua autoestima abalada. Assim, quanto mais balanceadas as relações de troca, maiores serão os benefícios físicos e psicológicos para o idoso (RAMOS, 2002).

Em estudo com idosos da América Latina, Saad (2004) observou que eles não apenas recebem, mas também prestam ajuda na forma de bens, serviços, dinheiro, etc., caracterizando claramente a transferência informal de apoio entre os idosos e a família, especialmente filhos e netos. Por mais que as transferências intergeracionais possam ser consideradas positivas, o autor chama a atenção para dois pontos importantes: por um lado, o intenso fluxo de ajuda familiar ao idoso substitui parcela importante dos cuidados que deveriam ser fornecidos pela sociedade via instrumentos formais; e, por outro, o fluxo no sentido inverso faz com que os filhos, importante fonte de auxílio econômico, passem a contar com os idosos, que arcam com o ônus de se tornarem fonte de ajuda informal para os seus familiares. Nesse processo de intercâmbio recíproco entre gerações, as transferências são mediadas por características, recursos, oportunidades e necessidades de cada geração.

Marteleto e Noonan (2001) investigaram o cuidado infantil fornecido pelas avós no Brasil. O estudo não focalizou apenas as avós idosas, podendo-se observar a importância das transferências entre as gerações. As crianças mais jovens e que vivem em domicílios de menor renda apresentam maiores chances de serem cuidadas pelas avós, quando se comparam outros tipos de cuidado infantil. Além disso, a probabilidade de a avó cuidar do neto é maior se a mãe da criança trabalha em horário integral. Em relação à co-residência, as autoras destacam que, para os netos que co-residem, as chances de serem cuidados pelas avós diminuem com o aumento da escolaridade da avó.

Segundo Aquino e Cabral (2002), está ocorrendo uma perda gradativa da centralidade da família, que deixa de ser uma instituição única e total, apresentando-se, cada vez mais, como parte da rede de relações sociais. Isso porque, desde o final do século $X X$, a sociedade tem valorizado mais a independência, existe maior facilidade de comunicação e locomoção e os idosos apresentam melhores condições de saúde.

Para Saad (2004), no contexto brasileiro e latino-americano, a co-residência pode ser considerada elemento importante no processo de transferências intrafamiliares de apoio. Afinal, uma parcela substancial das transferências se dá entre os membros de um mesmo domicílio. Segundo o autor, a co-residência, mais do que o número de filhos, é um dos fatores primordiais para garantir alguma forma de ajuda nas atividades funcionais do dia-a-dia. No caso dos municípios de São Paulo, Buenos Aires, Montevidéu e Cidade do México, o autor relata que a probabilidade de receber auxílio funcional entre os idosos que moram sozinhos é $63 \%$ menor em relação àqueles que co-residem com uma pessoa. Além disso, a coabitação tende a aumentar significativamente o fluxo de ajuda financeira, enquanto para os idosos que moram sozinho a probabilidade de receberem e prestarem ajuda financeira é bastante baixa. Assim, como salienta Glaser (1997), a co-residência, embora não seja um indicador suficiente para medir ajuda, pode ser considerada um importante instrumento facilitador para que as transferências ocorram entre os idosos e seus filhos.

Camarano e El Ghaouri (2003) consideram a co-residência uma estratégia das famílias para beneficiar tanto as gerações mais velhas como as mais jovens, podendo, no caso do Brasil, significar melhoria nas condições de vida. No entanto, apesar de o idoso brasileiro nos estratos mais pobres 
contribuir com sua renda para o sustento da família, nem sempre ele recebe o respaldo de que necessita, tanto por insuficiência de recursos quanto pelas dificuldades da família no cuidado com o idoso, por necessidades materiais, emocionais ou de informação (CALDAS, 2003). Muitas vezes, as condições do próprio idoso, sua família, a organização doméstica, o número de filhos, sua situação econômica, nível de renda, entre outros, podem influenciar de formas distintas para que a ajuda não se concretize (MONTES DE OCA, 2001).

Portanto, co-residir não garante amparo ao idoso em casos de dificuldade, apesar de a co-residência atuar como facilitador nas transferências. Por outro lado, o idoso que mora sozinho não está excluído de participar das transferências com os parentes que moram em outro domicílio.

Paralelamente à discussão das transferências entre as gerações, têm sido abordadas algumas características dos idosos que participam desse intercâmbio. Além de aspectos socioeconômicos, são tratadas, principalmente, características como sexo e estado conjugal. Quanto aos aspectos socioeconômicos, a análise de Saad (2004) para idosos residentes em São Paulo, Montevidéu, Buenos Aires e Cidade do México mostrou que a renda e a educação associam-se positivamente com a probabilidade de prestar ajuda financeira, e negativamente com a de receber esse tipo de ajuda. A probabilidade de um idoso receber auxílio em dinheiro diminui se ele não possui filhos vivos. Contudo, a ausência de filhos não afeta de forma significativa as chances de ele prestar ajuda financeira.

No que diz respeito às diferenças entre os sexos, comparadas aos homens, as mulheres apresentam probabilidade significativamente maior de receber e significativamente menor de fornecer ajuda financeira. Também observou-se que, apesar de as mulheres apresentarem maior risco de relatar dificuldade em atividades básicas e instrumentais da vida diária, se comparadas aos homens, a probabilidade de receber auxílio entre os que reportam dificuldade não difere significativamente entre os sexos.
Ainda no que se refere a gênero, Larsson e Thorslund (2002) analisaram as diferenças em relação ao tipo de cuidado recebido, formal ou informal, por idosos suíços residentes em áreas urbanas. Os resultados indicaram que, quando controlado apenas por incapacidade funcional e cognitiva, os homens tendem a apresentar menores chances de receber apoio formal (67\%) do que as mulheres. Entretanto, ao se controlar por arranjo domiciliar, as diferenças entre os sexos praticamente desaparecem. Segundo os autores, as diferenças quanto ao cuidado formal e informal se dão em relação ao tipo de estrutura domiciliar e não ao sexo do idoso.

Outro aspecto a se considerar nas transferências é o efeito da estrutura domiciliar, uma vez que ela, mais do que o sexo, parece influenciar o tipo de ajuda recebida, mesmo que existam diferenças em quem presta o cuidado ao idoso. No caso do estudo de Larsson e Thorslund (2002), se comparados aos idosos que moram sozinhos, aqueles que residem com o cônjuge e com outros parentes apresentam chances significativamente menores de receberem apoio formal (81\% e 68\%, respectivamente). Em contrapartida, para os que vivem sozinhos, as chances de receberem apoio informal são menores. Entretanto, apesar de não existirem diferenças entre os sexos em relação ao tipo de apoio recebido, há diferenças em quem presta auxílio informal ao idoso. Neste caso, os homens são assistidos preferencialmente pelas esposas, ao passo que as mulheres contam principalmente com a ajuda dos filhos, como apontado em estudo realizado no Brasil (CAMARGOS, 2004).

Segundo Aquino e Cabral (2002), de modo geral, os homens se beneficiam mais do que as mulheres da "proteção à saúde"decorrente do casamento, pois as mulheres idosas, mesmo fragilizadas, dão assistência ao cônjuge e demais membros da família. Assim, o apoio dos filhos é oferecido em maior medida às mães idosas do que aos pais, que geralmente são casados, já que o índice de viuvez é mais alto entre as mulheres, devido à própria sobremortalidade masculina. 
Sobre os divorciados, Pezzin e Schone (1999) argumentam que existem efeitos negativos do rompimento do casamento ao final do ciclo de vida. Os idosos divorciados apresentam menor nível de co-residência e recebem menor número de horas de cuidado informal por parte de seus filhos adultos, com maior impacto para os pais idosos do que para as mães idosas. Já em relação às pessoas idosas que nunca se casaram ou tiveram filhos, Larsson e Silverstein (2004) assinalam que, em geral, elas desenvolvem uma estratégia de estilo de vida independente extrafamiliar, ampliando suas relações com amigos e garantindo a manutenção de uma vida independente na velhice. Nesse caso, idosos que mantêm um contato frequente com os amigos apresentam maiores chances de receber apoio informal. Além disso, idosos que não possuem suporte social de familiares e amigos tendem a ter mais dificuldade para lidar com situações de estresse do que aqueles que têm tal suporte (RAMOS, 2002).

Em geral, os estudos que tratam as relações intergeracionais realçam a importância da co-residência nas transferências (YAZAKI, 1992; VARLEY; BLASCO, 2001). Neste caso, um idoso que mora com o cônjuge ou com os filhos e netos tenderia a apresentar maiores chances de receber cuidado informal. Já aqueles que moram sozinhos, apesar de participarem das transferências, estão menos propensos a receber este tipo de cuidado e com maiores chances de receberem cuidado formal. Embora as transferências possam se dar independentemente do arranjo domiciliar do idoso, as que ocorrem entre os membros de um mesmo domicílio parecem ser mais frequentes e, talvez por isso, mais discutidas.

Camargos (2008), com base em entrevistas em profundidade com idosos que moravam sozinhos no município de Belo Horizonte (MG), em 2007, revelou que, diferentemente da tônica vigente nos anos 1980 e 1990, os idosos entrevistados foram quase unânimes em destacar que, mesmo vivendo sozinhos, sentiam-se amparados por parentes ou amigos. Uma das conclusões do estudo foi que, ao que parece, não existiam idosos isolados, uma vez que haviam desenvolvido formas distintas de se relacionarem com familiares e amigos, mesmo se mantendo em domicílios unipessoais.

\section{Limitações do estudo}

Trata-se de revisão narrativa e não de revisão sistemática, de caráter descritivo-discursivo, a qual apresenta e discute temas de interesse científico (ATALLAH; CASTRO, 1997). A revisão narrativa permite ao leitor adquirir conhecimento sobre uma temática específica em um tempo curto, mas apresenta as desvantagens de não ser reprodutível, às vezes incompleta e, em alguns casos, inconclusiva (ATALLAH; CASTRO, 1997).

No caso do presente estudo, foram descritos e discutidos, de forma ampla, aspectos relacionados à conformação de domicílios unipessoais de idosos, não tendo sido objetivo deste trabalho responder a uma questão específica sobre estes domicílios.

Contudo, segundo Rother (2007), este tipo de manuscrito constitui-se, basicamente, de análise de literatura que serve ao propósito de interpretação e análise crítica e pessoal dos autores, podendo padecer de vieses relativos à seleção dos trabalhos analisados e à avaliação crítica e pessoal dos autores. Não obstante, neste trabalho procurou-se minimizar este viés por meio da inclusão de estudos contrastantes, que procuravam evidenciar visões diferenciadas sobre os aspectos que foram abordados.

Cabe ainda observar que, diferentemente da revisão sistemática, não se procurou neste trabalho integrar a informação existente sobre os idosos que moram sozinhos, por meio do agrupamento e análise dos resultados oriundos de outros estudos conduzidos em locais e momentos diferentes. É fato que isso permitiria a geração de evidência científica na temática dos idosos em domicílio unipessoal. Contudo, ainda é pequena a literatura sobre esse segmento populacional e seus arranjos domiciliares e poucos são os estudos primários conduzidos nesta temática, o que dificultaria qualquer tentativa de revisão sistemática mais criteriosa. Assim, neste contexto, a revisão narrativa consistiu na melhor alternativa. 


\section{Síntese e reflexões}

Morar sozinho, com o cônjuge, com filhos, outros parentes ou com uma pessoa de fora da família depende de uma série de fatores e de eventos que vão se conformando ao longo da vida do indivíduo. Para alguns idosos, o convívio com os familiares na mesma residência pode ser essencial, para ajudar a resolver questões do dia-a-dia (físicas ou financeiras), assim como para compartilhar a convivência diária. Para outros, o convívio pode ser indesejado e ser a única opção, em detrimento de uma institucionalização. Morar sozinho pode ser uma alternativa para idosos que lutam para manter sua independência e autonomia ou mesmo inevitável para aqueles que, apesar de se sentirem sós ou abandonados, não possuem outras pessoas com as quais possam co-residir.

Algumas questões importantes permanecem. Por exemplo, quais as estratégias adotadas pelo idoso que lhe permite viver sozinho? Quem faz parte da sua rede de apoio? Ao viver sozinho, o idoso adota um estilo de vida adequado a um bom estado de saúde?

$\mathrm{Na}$ verdade, ainda se sabe muito pouco sobre os idosos residentes em domicílios unipessoais, da forma como eles enfrentam

\section{Referências}

ANDRADE, F. C.; DE VOS, S. An analysis of living arrangements among elderly women in Brazil. In: ENCONTRO NACIONAL DE ESTUDOS POPULACIONAIS, 14, 2002, Caxambu. Anais... Campinas: Abep, 2002.

AQUINO, F. T. M.; CABRAL, B. E. S. O idoso e a família. In: FREITAS, E. V. et al. Tratado de geriatria e gerontologia. Rio de Janeiro: Guanabara Koogan, 2002, p. 1.056-1.060.

ATALLAH, N. A.; CASTRO, A. A. Revisões sistemáticas da literatura e metanálise: a melhor forma de evidência para tomada de decisão em saúde e a maneira mais rápida de atualização terapêutica. Diagnóstico \& Tratamento, v. 2, n. 2, p. 12-15, 1997.

AVERY, R.; SPEARE Jr.; A.; LAWTON, L. Social support, disability and independent as dificuldades do dia-a-dia, como procuram e prestam ajuda e quem faz parte de sua rede de suporte. Essas informações, no entanto, estão quase sempre ausentes das bases de dados disponíveis, uma vez que são mais apropriadamente obtidas por meio de pesquisas qualitativas. Neste escopo, esta revisão reforçou a importância e a necessidade de se estudar quais são e como se estruturam as redes de apoio e os arranjos domiciliares de pessoas idosas, uma vez que esses podem influenciar diretamente em sua qualidade de vida. Afinal, é nessa fase da vida que as dificuldades físicas, financeiras e afetivas tendem a surgir com maior intensidade.

Mesmo não representando a maioria entre os arranjos domiciliares de idosos no Brasil, a realidade dos idosos que vivem sozinhos deve ser considerada tanto por estudiosos como por aqueles que são responsáveis pelas políticas públicas. A Política Nacional do Idoso, desenhada para garantir direitos sociais desta população específica, deve acompanhar as mudanças em seu perfil de habitação e considerar que, ao longo dos anos, mais e mais idosos deverão viver sozinhos. Esta população, fragilizada ou não, requer apoio para seguir vivendo os anos que lhe restam, de forma independente ou assistida, com dignidade e bem-estar.

living of elderly person in the United States. Journal of Aging Studies, Greenwich, v. 3, n. 4, p. 279-293, 1989.

BERQUÓ, E. Algumas considerações demográficas sobre o envelhecimento da população no Brasil. In: SEMINÁRIO INTERNACIONAL SOBRE ENVELHECIMENTO POPULACIONAL: UMA AGENDA PARA O FIM DO SÉCULO, 1996, Brasília. Anais... Brasília, 1996, p. 16-34.

BERQUÓ, E.; CAVENAGHI, S. M. Oportunidades e fatalidades: um estudo demográfico das pessoas que moram sozinhas. In: ENCONTRO NACIONAL DE ESTUDOS POPULACIONAIS,11, 1988, Olinda. Anais... Belo Horizonte: Abep, v. 1, 1988, p.155-182. 
BONGAARTS, J.; ZIMMER, Z. Living arrangements of older adults in the developing world: an analysis of demographic and health survey household surveys. Journal of Gerontology, Washington, v. 57B, n. 3, p. S145-S157, May 2002.

CALDAS, C. P. Envelhecimento com dependência: responsabilidade e demandas da família. Cadernos de Saúde Pública, Rio de Janeiro, v. 19, n. 3, p. 773-781, maio/ jun. 2003.

CAMARANO, A. A.; EL GHAOURI, S. K. Famílias com idosos: ninhos vazios? Rio de Janeiro: Ipea, 2003. (Texto para Discussão, 950).

CAMARGOS, M. C. S. Estimativas de expectativa de vida livre de e com incapacidade funcional: uma aplicação do método de Sullivan para idosos paulistanos, 2000. Dissertação (Mestrado em Demografia) - Centro de Desenvolvimento e Planejamento Regional, Universidade Federal de Minas Gerais, Belo Horizonte, 2004.

Enfim só: um olhar sobre o universo de pessoas idosas que moram sozinhas no município de Belo Horizonte (MG), 2007. Tese (Doutorado em Demografia) Centro de Desenvolvimento e Planejamento Regional, Universidade Federal de Minas Gerais, Belo Horizonte, 2008.

CAMARGOS, M. C. S.; MACHADO, C. J.; RODRIGUES, R. N. A relação entre renda e morar sozinha para idosas mineiras, 2003. In: SEMINÁRIO SOBRE A ECONOMIA MINEIRA, 12, 2006, Diamantina. Anais... Belo Horizonte: Cedeplar, 2006.

A relação entre renda e morar sozinho para idosos paulistanos, 2000. Revista Brasileira de Estudos de População, Campinas, v. 24, n. 1, p. 37-51, jan./ jun. 2007.

CAMERON, L. The residency decision of elderly: a nested logit analysis. Demography, Chicago, v. 37, n. 1, p. 17-27, Feb. 2000.

CAMPOS, A. P. F. M. Algumas características do perfil dos domicílios unipessoais no Brasil, Sudeste e Nordeste, 1980-1991.
Dissertação (Mestrado em Demografia) Centro de Desenvolvimento e Planejamento Regional, Universidade Federal de Minas Gerais, Belo Horizonte, 1998.

FERREIRA, F. P. M. Estrutura domiciliar e localização: um estudo dos domicílios com idosos em Belo Horizonte. Tese (Doutorado em Demografia) - Centro de Desenvolvimento e Planejamento Regional, Universidade Federal de Minas Gerais, Belo Horizonte, 2001.

GLASER, K. The living arrangements of elderly people. Reviews in Clinical Gerontology, London, v. 7, n. 1, p. 63-72, Jan. 1997.

GLIKSMAN, M. D.; LAZARUS, R.; WILSON, A.; LEEDER, S. R. Social support, marital status and living arrangement correlates of cardiovascular disease risk factors in the elderly. Social Science and Medicine, Oxford, v. 40, n. 6, p. 811-816, Mar. 1995.

GOLDANI, A. M. Mulheres e envelhecimento: desafios para novos contratos intergeracionais e de gênero. In: CAMARANO, A. A. (Org.). Muito além dos 60: os novos idosos brasileiros. Rio de Janeiro: Ipea, 1999, p.75-113.

GUZMÁN, J. M.; MONTES DE OCA, V. Redes de apoyo social de personas mayores: marco teórico conceptual. In: SIMPOSIO VIEJOS Y VIEJAS: PARTICIPACIÓN, CIUDADANÍA E INCLUSIÓN SOCIAL. 2003. Santiago de Chile. Anais... Santiago de Chile: Cepal, 2003.

IBGE. Síntese de indicadores sociais: uma análise das condições de vida da população brasileira, 2007. Rio de Janeiro, 2007.

ILIFFE, S.; TAI, S. S.; HAINES, A.; GALLIVAN, S.; GOLDENBERG, E.; BOOROFF, A.; MORGAN, P. Are elderly living alone an at risk group? British Medical Journal, London v. 305, n. 6.860, p.1.001-1.004, Oct. 1992.

KINSELLA, K.; VELKOFF, V. A. Living arrangements. In: KINSELLA, K.; VELKOFF, V. A. An aging word: 2001. Washington: U. S. Government Printing Office, 2001, p. 6572. Disponível em: <http://www.census.gov/ prod/2001 pubs > . Acesso em: 11 ago. 2004. 
KRAMAROW, E. A. The elderly who live alone in United States: historical perspectives on household change. Demography, Chicago, v. 32, n. 3, p. 665-353, Aug. 1995.

LARSSON, K.; SILVERSTEIN, M. The effects of marital and parental status on informal support and service utilization: a study o folder Swedes living alone. Journal of Aging Studies, New York, v. 18, n. 2, p. 231-244, May 2004.

LARSSON, K.; THORSLUND, M. Does gender matter? Differences in patterns of informal support and formal services in a Swedish urban elderly population. Research on Aging, Thousand Oaks, Calif, v. 24, n. 3, p. 308-336, May 2002.

MARTELETO, L. J.; NOONAM, M. C. Las abuelas como proveedoras de cuidado infantil en Brasil. In: GOMES, C. (Comp.). Procesos sociales, población y familia: alternativas teóricas y empíricas en las investigaciones sobre vida doméstica. México: Facultad Latinoamericana de Ciencias Sociales, 2001, p. 377-394.

MCGARRY, K.; SCHOENI, R. F. Social security, economic growth, and the rise in elderly widow's independence in the twentieth century. Demography, Chicago, v. 37, n. 2, p. 221-236, May 2000.

MONTES DE OCA, V. Bienestar, familia y apoyos sociales entre la población anciana en México: una relación en proceso de definición. In: GOMES, C. (Comp.). Procesos sociales, población y familia: alternativas teóricas y empíricas en las investigaciones sobre vida doméstica. México: Facultad Latinoamericana de Ciencias Sociales, 2001, p. 345-376.

NERI, M. C. Sexo, casamento e economia. Rio de Janeiro: FVG/IBRE, 2005. Disponível em: <http://www.fgv.br/cps>. Acesso em: 09 jun. 2005.

PEZZIN, L. E.; SCHONE, B. S. Parental marital disruption and intergenerational transfers: an analysis of alone elderly parents and their children. Demography, Chicago, v. 36, n. 3, p. 287-297, Aug. 1999.
RAMOS, M. P. Apoio social e saúde entre os idosos. Sociologias, Porto Alegre, n. 7, p. 156-175, jan./jun. 2002.

ROMERO, D. E. Diferenciais de gênero no impacto do arranjo familiar no status de saúde dos idosos brasileiros. Ciência \& Saúde Coletiva, Rio de Janeiro, v. 7, n. 4, p. 777-794, 2002.

ROTHER, E. T. Editorial: Revisão sistemática $X$ revisão narrativa. Acta Paulista de Enfermagem, São Paulo, v. 20, n. 2, p. v-vi, 2007.

SAAD, P. M. Arranjos domiciliares e transferências de apoio informal. In: LEBRÃO, M. L.; DUARTE, Y. A. O. (Orgs.). O projeto SABE no Brasil: uma abordagem inicial. Brasília: Organização Pan-Americana da Saúde, 2003, p. 203-224

Transferências de apoio entre gerações no Brasil: um estudo para São Paulo e Fortaleza. In: CAMARANO, A. A. (Org.). Muito além dos 60: os novos idosos brasileiros. Rio de Janeiro: Ipea, 1999, p.251-280.

Transferências de apoio intergeracional no Brasil e na América Latina. In: CAMARANO, A. A. (Org.). Os novos idosos brasileiros: muito além dos 60 ? Rio de Janeiro: Ipea, 2004, p. 169-209.

UNITED NATIONS. Living arrangements of older persons around the world. New York, 2005.

VARLEY, A.; BLASCO, M. ¿Cosechan Io que siembran? Mujeres ancianas, vivienda y relaciones familiares en el México urbano. In: GOMES, C. (Comp.). Procesos sociales, población y familia: alternativas teóricas y empíricas en las investigaciones sobre vida doméstica. México: Facultad Latinoamericana de Ciencias Sociales, 2001, p. 301-323.

YAZAKI, L. M. Arranjos familiares e a presença da mulher no apoio aos idosos. In: ENCONTRO NACIONAL DE ESTUDOS POPULACIONAIS, 8, 1992, Brasília. Anais... São Paulo: Abep, v. 2, 1992, p. 297-308. 


\section{Resumen}

Anciano, familia y domicilio: una revisión narrativa sobre la decisión de vivir solo

En este artículo se intentan establecer una bases de argumentación para entender mejor las razones que llevan a un anciano a vivir solo y cómo se procesan las transferencias (flujo de recursos, acciones e información que se intercambia y circula) cuando vive solo. Para ello, se revisan y discuten factores determinantes del manejo de los domicilios de los ancianos, incluyendo aspectos demográficos, socioeconómicos y de salud, con énfasis en los domicilios unipersonales. Se destacan puntos que van más allá de las transferencias entre ancianos y sus familiares, tales como características de las transferencias intergeneracionales, diferencias entre los diversos apoyos recibidos, sexo del anciano. El estudio consistió en una revisión narrativa, cuyos resultados apuntaron que unas mejores condiciones socioeconómicas y de salud, edad más avanzada y ausencia de hijos parecen contribuir a que el anciano viva solo. Sin embargo, hubo divergencias en los resultados de los estudios analizados, en cuanto a los factores asociados a la formación de domicilios unipersonales de enfermos. Pese a que las transferencias puedan producirse independientemente del manejo del domicilio del anciano, las que se producen entre los miembros de un mismo domicilio parecen ser más frecuentes y, tal vez por esto, más discutidas. Los ancianos que viven solos, a pesar de que participan en las transferencias, son más propensos a recibir cuidado formal, en comparación con aquellos que residen con otras personas.

Palabras-clave: Ancianos. Domicilios unipersonales. Familia.

\section{Abstract \\ Elderly persons, family and household: a narrative review of the decision to live alone}

The authors seek to establish bases of argumentation in order to better understand the reasons that lead elderly citizens to live alone and how transfers take place (flow of resources, actions and information that is exchanged and circulated) when such persons do live alone. Determining factors are reviewed and discussed regarding the household arrangements of elderly citizens, including demographic, socioeconomic and health factors, with emphasis on single-person households. Factors that permeate transfers between elderly citizens and their families are underscored, such as the characteristics of intergenerational transfers, differences among the various types of support provided, and the gender of the elderly persons. The study consists of a narrative review and the results indicate that comfortable socioeconomic and health conditions, more advanced age and lack of children seem to contribute to an elderly person's decision to live alone. However, there were differences in the results of the studies analyzed in terms of the factors associated with the formation of single-person households among elderly persons. Although transfers generally take place regardless of the elderly person's household arrangements, those that take place among members of a single household seem to be more frequent and, perhaps for this reason, are discussed at greater length. Even when elderly persons who live alone participate in transfers, they are more likely to receive formal care than those who live with other persons.

Keywords: Elderly persons. Single-person households. Family. 